\title{
Medios de almacenamiento y transporte para dientes avulsionados
}

Transport and Storage means for avulsed teeth

\begin{abstract}
Resumen
Se realizó una revisión de la literatura con respecto a los medios de almacenamiento para dientes avulsionados. Se utilizó el buscador Medline, incluyendo aquellas publicaciones entre 1980 - 2007 en las que apareciesen como palabra clave: "viability", "storage medium", "storage media", "tooth avulsion" y "avulsion". Los mejores medios son aquellos que tienen las siguientes características: $\mathrm{pH}$ y osmolalidad fisiológica, contengan nutrientes, sean líquidos estériles y estén disponibles en el lugar del accidente. Los resultados de estos estudios muestran que la leche fresca descremada pasteurizada fue mejor que la saliva, el agua, las soluciones para lentes de contacto y el Gatorade®. El HBSS y el Viaspan fueron mejores que la leche, el propóleo y el agua de coco. El Viaspan fue igual a, o mejor que, el HBSS para preservar las células del ligamento periodontal. A pesar de su efectividad en mantener la viabilidad celular, el Viaspan y el HBSS son costosos y no están disponibles rápidamente en el lugar del accidente a diferencia de la leche.
\end{abstract}

\begin{abstract}
A review of the literature was made regarding the way avulsed teeth were stored. An online search in Medline was used, including those publications between 1980 and 2007 in which the key word: "viability", "storage medium", "storage media", "tooth avulsion" and "avulsion" appeared. The best storages are those that have the following characteristics: $\mathrm{pH}$ and physiological osmolality, contain nutrients, are liquid sterile and are available at the moment of the accident. The results of those studies showed that low-fat fresh milk pasteurized was better than saliva, water, contact lens solutions and the Gatorade ${ }^{\circledR}$. HBSS and Viaspan were better than milk, propolis and tender Coconut water. Viaspan was equal to, or better than, HBSS in preserving periodontal ligament cells. Unfortunately, despite of its effectiveness in maintaining periodontal ligament cells viability, Viaspan and HBSS are expensive and are not available like milk.
\end{abstract}

\section{Introduccion}

Los traumatismos dentarios en niños son el segundo motivo de consulta después de la Caries Dental y son un problema de salud pública, no porque su prevalencia sea alta, sino por las secuelas que ocasiona. ${ }^{1}$

El tratamiento de la avulsión es el reimplante, pero el porcentaje de éxito a largo plazo varía entre el $4-70 \%$, ya que va a depender de las condiciones clínicas específicas de cada caso en particular. ${ }^{2,3}$ Para el pronóstico los factores críticos son:

- El período extraoral (Tiempo que el diente está fuera de boca $=$ Tiempo en medio seco + tiempo en medio húmedo).

- El medio de almacenamiento (porque los fibroblastos al no estar irrigados se desecan rápidamente).
El tiempo en medio seco es el factor clínico más asociado con el desarrollo de la anquilosis post-reimplante o reabsorción de reemplazo. ${ }^{2,3,4,5}$

\section{Objetivos}

Realizar una revisión de la literatura publicada usando el enfoque basado en evidencia para actualizar la información con respecto a los medios de almacenamiento para dientes avulsionados.

\section{Métodos empleados}

Se analizaron los estudios publicados en la bibliografía médica, utilizando el buscador Medline, considerando aquellas publicaciones en las que apareciesen como palabra clave: "viability", "storage medium", "storage media", "tooth avulsion" y "avulsion". Se incluyeron 26 publicaciones

\section{Carmen Inocencia Quintana del Solar ${ }^{1}$}

Departamento Académico de Estomatología Pediátrica. Facultad de Odontología de la UNMSM. Lima - Perú.

Correspondencia:

CD Carmen Inocencia Quintana del Solar Facultad Odontología, UNMSM

Av. German Amezaga s/n, Lima, 1 Perú. e-mail: cquintanad@unmsm.edu.pe

Palabras clave: Traumatismos de los dientes, avulsión dentaria, medios de transporte.

Key words: Tooth injuries, tooth avulsion, storage medium.

entre 1980 y el 2007. Se excluyeron los artículos sin resumen disponible y los casos clínicos. Las referencias adicionales son de los libros de texto $\mathrm{y}$ tesis.

\section{Medios de almacenamiento y transporte}

El factor más crítico relacionado con el pronóstico desfavorable después del reimplante parece ser el medio de almacenamiento del diente avulsionado previo al reimplante. Es importante que los fibroblastos del ligamento periodontal adheridos a la raíz se mantengan húmedos. Los estudios demuestran que la cantidad de células viables del ligamento periodontal declinan muy rápidamente con el aumento del tiempo en medio seco. ${ }^{7}$

Si el reimplante inmediato no es posible, el adulto responsable del niño deberá poner rápidamente el diente 
avulsionado en un medio adecuado hasta la consulta de urgencia. Muchos medios $^{7-30}$ han sido sugeridos para preservar la viabilidad de las células del ligamento periodontal, pero éstos deben tener las siguientes características (Figura 1):

- pH balanceado, pues existe crecimiento celular en un $\mathrm{pH}$ entre 7,2 a 7,4 , pero se ha demostrado que existe viabilidad celular por períodos largos de tiempo con un rango de $\mathrm{pH}$ entre 6,6 y $7,8 .^{8}$

- Osmolalidad fisiológica, pues se ha reportado que el crecimiento celular ocurre en un rango de 230 - $400 \mathrm{mOsm} / \mathrm{Kg}$, sin embargo el crecimiento celular óptimo sucede en un rango de 290 a $330 \mathrm{mOsm} /$ Kg. ${ }^{8}$

- En su composición deben tener elementos que nutran las células del ligamento periodontal que aún permanecen viables. ${ }^{19}$

- Ser líquidos estériles, pues la contaminación bacteriana está relacionada con la reabsorción inflamatoria. ${ }^{19}$

- Estar disponibles en el lugar del accidente. ${ }^{8-28}$

En las investigaciones publicadas730 se han estudiado una variedad de medios de almacenamiento por su capacidad para mantener la viabilidad de las células del ligamento periodontal (Cuadro 1). Estos medios fueron comparados por su efectividad en preservar la viabilidad de los fibroblastos del ligamento periodontal:

- Agua: La osmolalidad del agua varía de 3 - $16 \mathrm{mOsm} / \mathrm{Kg}$ y su $\mathrm{pH}$ es de $7,41^{4,20}$ es el medio de transporte menos adecuado pues al ser hipotónica desencadena la lisis celular, adicionalmente el almacenamiento en agua más de veinte minutos provoca grandes reabsorciones radiculares $14,20,23,25,27,29$

- Saliva: Por tener una osmolalidad de 60 - 80 mOsm/Kg y pH de 6,76 - 7,3512-16,19,20 como por contener bacterias no es muy idónea. No obstante, los estudios demuestran que si el diente se pone en el vestíbulo bucal, los fibroblastos pueden mantenerse vitales unas dos horas. Pero tanto el agua como la saliva alteran la estructura del fibroblasto, por lo que no son aconsejables como medio de transporte del diente, aunque son mejores que hacerlo en seco. $7,10,12-$ $16,18,20,21$

- Suero fisiológico: Tiene una osmolalidad de 280 - 285 mOsm/ $\mathrm{Kg}$, un $\mathrm{pH}$ de $7,0^{13,18}$ y es estéril, por lo que es un medio de conservación aceptablea corto plazo, manteniendo la vitalidad celular unas tres horas. $3,7,11,14,18,19,24,26$

- Solución balanceada de HanK's (HBSS): Es un medio de cultivo estándar usado en la investigación biomédica para la conservación celular. Tiene un $\mathrm{pH}$ de 7,2 y su osmolalidad es de $270-320$ mOsm $/ \mathrm{Kg}^{8,19}$, evita la reabsorción radicular en un $91 \%$. En algunos países está comercializado en farmacias (Save-a-Tooth ${ }^{\circledR}$ Sat), como un pequeño contenedor con una canastilla interna que evita al mínimo el daño al ligamento periodontal durante el transporte, contiene solución de Hank's, para que el diente pueda ser introducido mientras se acude a la consulta dental para el reimplante, la desventaja es que es costoso y tiene una caducidad de dos años. 8,9

HBSS ha sido estudiado en profundidad mostrando que en las primeras 24 horas de almacenamiento, los fibroblastos se mantienen vitales, por lo que la reabsorción es escasa; y que después de 4 días de almacenamiento los dientes presentan reabsorción moderada. Además los fibroblastos no presentan distorsión en su morfología y tienen aspecto normal. El empleo de HBSS ha sido evaluado con éxito y siempre se suele utilizar como control positivo en estudios de medios de almacenamiento. $3,11,21,22,24,26,27,29$

- Medio de cultivo de Eagles: Tiene una osmolalidad de 291-315 mOsm/Kg y un pH de 7,2-7,4 14,19,22, se emplea en la investigación biomédica como medio de cultivo celular y como control positivo en viabilidad celular. ${ }^{8,12,14,16,18-23,25,27,29,30}$

- Viaspan: Tiene una osmolalidad de $320 \mathrm{mOsm} / \mathrm{K}$ y un pH de 7,422 se utiliza como medio de transporte para el transplante de órganos. El medio de Eagles y el Viaspan ofrecen resultados similares, incluso mejores, pero no están disponibles comercialmente para el público en general. $^{22}$
- Gatorade ${ }^{\circledR}$ : Es una bebida que puede estar más disponible en el lugar del accidente (canchas deportivas). Tiene entre 355 - 407 mOsm/Kg y un $\mathrm{pH}$ de 320 , los estudios son contradictorios, pues unos concluyen que en Gatorade ${ }^{\circledR}$ no se mantiene la vitalidad celular ${ }^{8,20}$ y otros refieren que el Gatorade ${ }^{\circledR}$ refrigerado podría servir para períodos cortos de almacenaje de dientes avulsionados. ${ }^{27}$

- Soluciones conservantes de lentes de contacto: Se han realizado estudios con Opti-free (ALCON) ${ }^{19,27,30}, \mathrm{~K}$ Mart $^{19}$, Soft-wear (CIBA-VISION) ${ }^{27}$, Solo-care (CIBA-VISION) ${ }^{27}$, Renu (BAUSCH AND LOMB) $^{30}$, Titmus $(\mathrm{CIBA}-\mathrm{VISION})^{30}$, pero en general refieren que conservan las células del ligamento periodontal por períodos cortos de tiempo.

- Agua de Coco: Dentro de los parámetros de un estudio reciente concluyeron que el agua de coco también es un adecuado medio de almacenamiento. $^{28}$

- Propóleo: Es una sustancia resinosa utilizada por las abejas para cubrir y proteger la colmena, la obtienen a partir de las yemas de algunos árboles. Contiene aminoácidos, oligoelementos, vitaminas, minerales y aceites esenciales; tiene 500 veces más bioflavonoides que las naranjas. Gracias a la acción antibiótica del propóleo, que protege de la actividad de virus y bacterias, la colmena es uno de los lugares más estériles conocidos en la naturaleza. No obstante, estudios científicos han demostrado que el efecto del propóleo se consigue gracias a la acción sinérgica de todos sus componentes y concluyen que es tan efectivo como la leche y el HBSS. ${ }^{26,29}$

- Leche: En 1981 Andreasen (Dinamarca) y Blomlof, Lindskog y Hammarstrom (Suecia) fueron los primeros en reportar sobre la viabilidad de la leche fresca descremada pasteurizada como medio para conservar un diente avulsionado. La leche si no fuera por el contenido de lípidos $3,20,23,25$ sería un excepcional medio; no obstante, en las condiciones en que se produce un traumatismo dentario es el mejor medio de transporte porque es fácil de conseguir y porque es un líquido estéril debido a la pasteurización 
$\mathrm{u}$ otros procesos de higienización de la leche (apertización para la leche evaporada y UHT para la leche en envases tetrapak). Hasta la actualidad se han realizado investigaciones con leche de diferentes composiciones. ${ }^{8-28}$ Los estudios reportan diferente $\mathrm{pH}$, osmolalidad y tiempo de almacenamiento dependiendo de la muestra de leche investigada, pero todos concuerdan que la leche es un adecuado medio de transporte que puede estar disponible en el lugar del accidente (cuadro 1, 2).

Los estudios reportan que la leche conserva la vitalidad de un buen número de fibroblastos durante tres a seis horas, período suficiente para que el paciente llegue a la consulta dental y se le realice el reimplante. ${ }^{17}$ Sin embargo, sólo previene la muerte celular, pero no restituye la forma ni restablece la capacidad mitótica de las células. ${ }^{2,21,25}$ Estudios recientes indican que a nivel celular el almacenamiento en leche es similar a la solución de Hank's, siempre que el período en seco no exceda de treinta minutos. Por tanto, la leche es un muy buen medio de almacenamiento a corto plazo, si se coloca el diente en ella como máximo media hora después del trauma. ${ }^{3,8-28} \mathrm{Si}$ la leche no estuviera disponible inmediatamente, una combinación de un breve almacenaje en saliva con subsiguiente almacenaje en leche es mejor que almacenarlo solo en saliva. ${ }^{3,12}$

Respecto a la temperatura de transporte, los estudios no son concordantes; pues unos aconsejan conservar en leche a temperatura ambiente $\left(20^{\circ} \mathrm{C}\right)$ y otros proponen leche fría $\left(4^{\circ} \mathrm{C}\right)$ para mantener la capacidad clonogénica celular.3,19,21,22,27

Cuadro 1: Medios de transporte, características físico-químicas, tiempo de almacenamiento y desventajas

\begin{tabular}{|c|c|c|c|c|}
\hline \multirow{2}{*}{ Medios de transporte } & \multicolumn{2}{|c|}{ Características físico-químicas } & \multirow{2}{*}{$\begin{array}{c}\text { Tiempo de } \\
\text { Almacenam.(hrs.) }\end{array}$} & \multirow{2}{*}{ Desventaja } \\
\hline & $\mathrm{pH}$ & $\begin{array}{l}\text { Osmolalidad } \\
\text { (mOsm/Kg) }\end{array}$ & & \\
\hline Agua & 7,4 & $3-16$ & $20^{\prime}$ & Hipotónica, reabsorción radicular \\
\hline Saliva & $6,76-7,35$ & $60-80$ & 2 & Contiene bacterias \\
\hline Suero fisiológico & 7,0 & $280-285$ & 3 & No contiene nutrientes \\
\hline HBSS & 7,2 & $270-320$ & 1-4 días & Costoso, no disponible \\
\hline Eagles & $7,2-7,4$ & 291-315 & 1-4 días & Costoso, no disponible \\
\hline Viaspan & 7,4 & 320 & 1-4 días & Costoso, no disponible \\
\hline Gatorade ${ }^{\circledR}$ & 3 & $355-407$ & Contradictorio & Acidez, 3 estudios \\
\hline Sol lentes contacto & -- & -- & Contradictorio & 3 estudios, no disponible \\
\hline Agua de coco & -- & -- & $45^{\prime}$ & 1 estudio, no disponible \\
\hline Propóleo & -- & -- & $45^{\prime}$ & 2 estudios, no disponible \\
\hline Leche & $6,1-6,8$ & $242-313$ & $3-6$ & Contenido de grasa \\
\hline
\end{tabular}

Cuadro 2: Clasificación de la leche, características físico-químicas y tiempo de almacenamiento

\begin{tabular}{|c|c|c|c|c|}
\hline \multirow{2}{*}{$\begin{array}{l}\text { Clasificación de la leche por el } \\
\text { contenido de grasa y el proceso } \\
\text { de higienización }\end{array}$} & \multicolumn{2}{|c|}{ Características físico-químicas } & \multirow{2}{*}{$\begin{array}{l}\text { Tiempo de } \\
\text { Almacenamiento } \\
\text { (hrs.) }\end{array}$} & \multirow{2}{*}{$\begin{array}{c}\text { Referencias } \\
\text { bibliográficas }\end{array}$} \\
\hline & $\mathrm{pH}$ & $\begin{array}{l}\text { Osmolalidad } \\
\text { (mOsm/Kg) }\end{array}$ & & \\
\hline $\begin{array}{l}\text { Leche fresca descremada } \\
\text { pasteurizada }\end{array}$ & $6,4-6,8$ & $242-278$ & $3-6$ & $9-22,27$ \\
\hline $\begin{array}{l}\text { Leche fresca semidescremada } \\
\text { pasteurizada }\end{array}$ & $6,68-6,75$ & 277 & 3 & 20 \\
\hline $\begin{array}{l}\text { Leche fresca entera } \\
\text { pasteurizada }\end{array}$ & $6,6-6,72$ & $273-277$ & $3 / 4-4$ & $8,20,23-26,28$ \\
\hline Leche UHT descremada & -- & -- & $1-6$ & 29 \\
\hline Leche UHT entera & 6,7 & 270 & $1-4$ & 18,23 \\
\hline Leche en polvo & 6,5 & 292 & 1 & 25 \\
\hline Enfamil ${ }^{\circledR}$ & 6,6 & 323 & 4 & 25 \\
\hline Similac ${ }^{\circledR}$ & 6,3 & 294 & 2 & 25 \\
\hline Leche evaporada entera & 6,1 & 313 & 1 & 25 \\
\hline
\end{tabular}




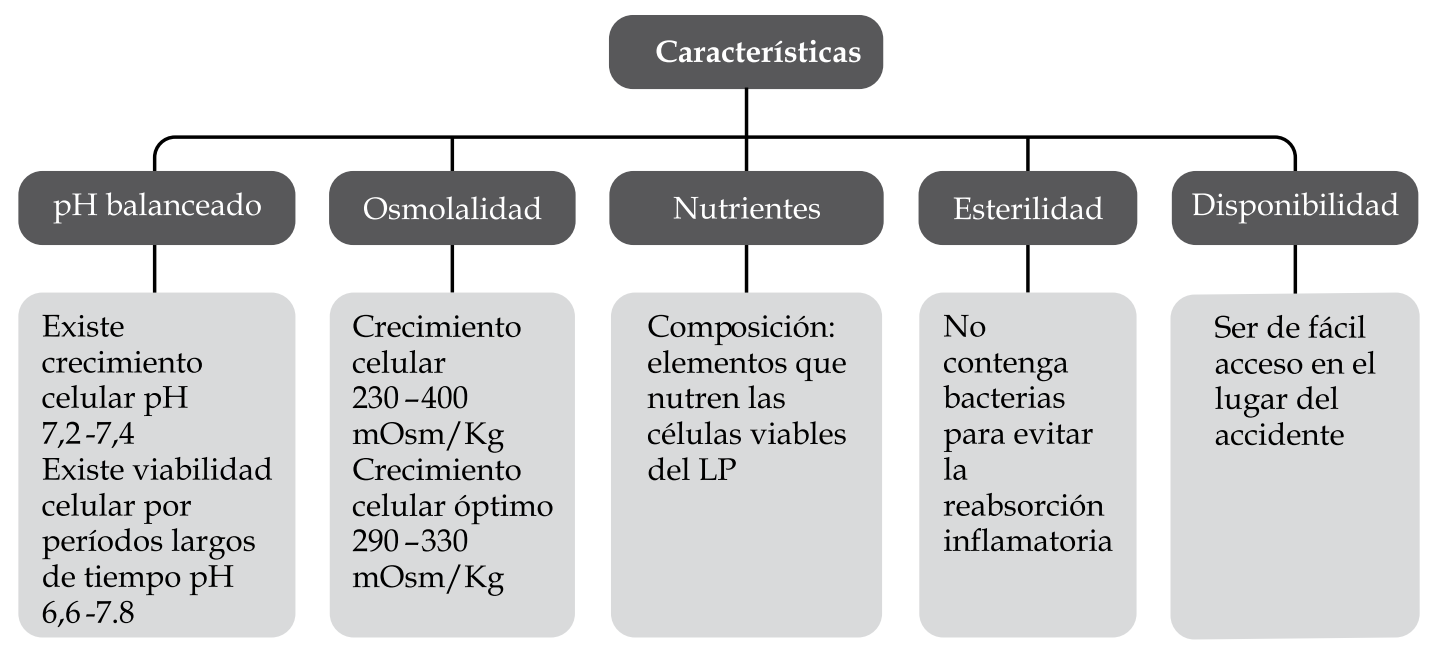

Figura 1: Características de los medios de transporte para dientes avulsionados

Al término de la presente revisión se llega a las siguientes conclusiones:

- Aunque con algunas diferencias, en general, los resultados de estos estudios muestran que la leche fresca descremada pasteurizada fue mejor que la saliva, el agua, las soluciones para lentes de contacto y el Gatorade ${ }^{\circledR}$. El HBSS y el Viaspan fueron mejores que la leche, el propóleo y el agua de coco. El Viaspan fue igual a, o mejor que, el HBSS para preservar las células del ligamento periodontal. Desafortunadamente a pesar de su efectividad en mantener la viabilidad celular del ligamento periodontal, el Viaspan y el HBSS son costosos y no están disponibles rápidamente en el lugar del accidente a diferencia de la leche.

- La leche tiene osmolalidad fisiológica, pH balanceado, es estéril, provee de nutrientes a los fibroblastos del ligamento periodontal y es de fácil disponibilidad, por lo que se puede considerar a la leche como el medio de almacenamiento adecuado, de preferencia se debe emplear la leche fresca descremada pasteurizada.

- En el Perú no se han publicado estudios sobre la viabilidad de los fibroblastos del ligamento periodontal en los medios revisados en este artículo, considerando que en nuestro país la producción y el consumo de leche evaporada entera $^{31}$ es superior a cualquier otro producto de la leche, es aconsejable investigar sus características físico- químicas y evaluar la viabilidad de las células del ligamento periodontal.

\section{Referencias bibliograficas}

1. Andreasen JO, Andreasen FM. Dental Traumatology: Quo Vadis. Endod Dent Traumatol 1990;6:78.

2. Andreasen JO, Andreasen FM. Lesiones Dentarias Traumáticas. España; Editorial Médica Panamericana. 1990.

3. García BC, Mendoza MA. Traumatología oral en Odontopediatría. Diagnóstico y tratamiento integral. España; Editorial Ergon; 2003.

4. Andreasen JO, Andreasen FM, Skeie A, Hjorting-Hansen E, Scwartz O. Effect of treatment delay upon pulp and periodontal healing of traumatic dental injuries - a review article. Dent Traumatol. 2002;18:116-128.

5. Donaldson M, Kinirons MJ. Factors affecting the time of onset of resorption in avulsed and replanted incisor teeth in children. Dent Traumatol. 2001;17(5):205-209.

6. Jacobsen I, Modeer T. Lesiones Traumáticas. En: Koch G, Modeér T, PoulsenS, RasmussenP.Odontopediatría Enfoque Clínico. España; Editorial Médica Panamericana. 1994:167-185.

7. Schwartz O, Andreasen FM, Andreasen JO. Effects of temperature, storage time and media on periodontal and pulpal healing after replantation of incisors in monkeys. Dent Traumatol. 2002;18:190195.

8. Olson BD, Mailhot JM, Anderson RW, Shuster GS, Weller RN. Comparison of various transport media on human periodontal ligament cell viability. J Endod. 1997;23(11)676-679.
9. Trope M. Tratamiento Clínico de la Avulsión. Clin Odontol de Norteam. 1995;1:87-106.

10. Blomlof L, Otteskog P. Viability of human periodontal ligament cells after storage in milk or saliva. Scand J Dent Res. 1980 Oct;88(5):436-40.

11. Blomlof L, Otteskog P, Hammarström L. Scand J Dent Res. 1981;89(2):180-7.

12. Blomlof L. Storage of human periodontal ligament cells in a combination of different media. J Dent Res. 1981;60(11):1904-1906.

13. Blomlof L, Lindskog S, Hammarstrom L. Periodontal healing of exarticulated monkey teeth stored in mil or saliva. Scand J Dent Res. 1981;89(3):251-259.

14. Lindskog S, Blomlof L. Influence of osmolality and composition of some storage media on human periodontal ligament cells. Acta Odontol Scand. 1982;40(6):435-441.

15. Blomlof L, Lindskog S, Andersson L, Hedström kg, Hammarstrom L. Storage of experimentally avulsed teeth in milk prior to replantation. J Dent Res. 1983;62(8):912-916.

16. Lindskog S, Blomlof L, Hammarstrom L. Mitoses and microorganisms in the periodontal membrane after storage in milk or saliva. Scand J Dent Res. 1983;91(6):465-472.

17. Hammarstrom L, Pierce A, Blomlof L, Feiglin B, Lindskog S. Tooth avulsion and replantation - a review. Endod Dent Traumatol. 1986 Feb;2(1):1-8.

18. Pongsiri S, Schegel D, Zimmerman M. Survival rate of periodontal ligament cells after extraoral storage in different media. Dtsch Z Mund Kiefer Gesichtschir. 1990 Sep-Oct;14(5):364368 . 
19. Huang SC, Remeikis NA, Daniel JC. Efectos de exposición prolongada de células de ligamento periodontal humano en leche y otras soluciones. Journal of Endodontics-Edición en Español. 1996;2(2):26-30.

20. Harkacz OM, Cames DL, Walter wa Determination of Periodontal Ligament Cell Viability in the Oral Rehydration Fluid Gatorade and Milks of varying fat content. J Endod. 1996;22(1):30-33.

21. Lekic PC, Kenny D, Barrett EJ. The influence of storage conditions on the clonogenic capacity of periodontal ligament cells: implications for tooth replantation. Int End J. 1998 Mar;31(2):137-40.

22. Ashkenazi M, Sarnat H, Keila S. In vitro viability, mitogenicity and clonogenic capacity of periodontal ligament cells after storage in six different media. Endod \& Dent Traumatol. 1999;15(4):149-156.
23. Marino TG, et al. Determination of Periodontal Ligament Cell Viability in Long-Shelf Milk. J Endod. 2000;26(12):699-702.

24. Pileggi R, Dumsha TC, Norje. Assesment of post - traumatic PDL cells viability by a novel collagenase assay. Dent Traumatol. 2002 Aug;18(4):186-189.

25. Pearson RM, Liewhr FR, West LA, Patton WR, McPherson JC, Runner RR. Human periodontal ligament cell viability in milk and milk substitutes. J Endod. 2003;29(3):184-186.

26. Martin MP, Pilleggi R. A quantitative analysis of Propolis: a promising new storage media following avulsion. Dent Traumatol. 2004 Apr;20(2):85-89.

27.Sigalas E, Regan JD, Kramer PR, Whiterspoon DE, Opperman LA. Survival of human periodontal ligament cells in media proponed for transport of avulsed teeth. Dent Traumatol. 2004;20(1):21-28.
28. Sunil O. Comparative Evaluation of Post-Traumatic Periodontal Ligament Cells viability using Four Different Storage Media - An in Vitro Study. [Dissertation for degree of Master of Dental Surgery in Conservative Dentistry]; The Tamil Nadu Dr. M.G.R. Medical University; 2005.

29. Ozan F, Polat ZA, Er K, Ozan U, Değer O. Effect of propolis on survival of periodontal ligament cells: new storage media for avulsed teeth. J Endod. 2007 May;33(5):570-573.

30. Al-Nazhan S, Al-Nasser A. Viability of human periodontal ligament fibroblasts in tissue culture after exposure to different contact lens solutions. J Contemp Dent Pract. 2006 Sep 1;7(4):37-44.

31. Martínez LJ. Programación de la Producción: Caso Leche Evaporada [tesis para optar el título de Ingeniero en Industrias Alimentarias] Universidad Agraria La Molina; 2000.

Recibido :05-10-2007

Aceptado para publicación: 30-10-2007 